\title{
Determination of selected components in seminal plasma of donkey stallions and their correlation to semen quality parameters
}

\author{
Michal Vyvial ${ }^{1}$, Eliška Horáčková ${ }^{1}$, Markéta Sedlinská1, Eva Jánová², \\ Śarka Krisová ${ }^{1}$, Miroslava Mráčková ${ }^{1}$ \\ University of Veterinary and Pharmaceutical Sciences Brno, \\ ${ }^{1}$ Faculty of Veterinary Medicine, Equine Clinic, ${ }^{2}$ CEITEC, \\ Department of Animal Genetics, Brno, Czech Republic
}

Received April 3, 2019

Accepted October 29, 2019

\begin{abstract}
Evaluation of selected components of seminal plasma as markers of ejaculate quality may be of interest when assessing the quality of semen. The aim of the study was to evaluate some biochemical parameters of seminal plasma in donkeys and compare them with the volume, concentration and motility of the ejaculate. A total of 11 ejaculates were collected from five donkey stallions (between one and three from each animal). Each ejaculate was assessed for volume, concentration and motility, and the seminal plasma biochemically examined after centrifugation. Total protein, creatinine, urea, alkaline phosphatase (ALP), alanine-aminotransferase (ALT), aspartate-amino-transferase, creatine kinase, gamma-glutamyl-transferase, lactate-dehydrogenase $(\mathrm{LDH})$, sodium, potassium $\left(\mathrm{K}^{+}\right)$, calcium, phosphate, chloride, copper $(\mathrm{Cu})$, cholesterol, vitamin E (Vit E), magnesium $\left(\mathrm{Mg}^{2+}\right)$, seminal plasma selenium (Se SP) and seminal plasma zinc (Zn SP) were identified. Biochemical analysis of the seminal plasma was then statistically evaluated using the Spearman coefficient of correlation. A significant positive correlation between ALP, ALT, LDH, Cu, Se SP and Zn SP and sperm concentration was found. Also there was a significant positive correlation between Vit E and sperm motility. Finally, there was a significant positive correlation between urea, $\mathrm{K}^{+}, \mathrm{Mg}^{2+}$ and the ejaculate volume. This is the first report about selected biochemical components of donkey's seminal plasma that we know of. However, further research using a larger number of individuals is necessary to confirm that these components of seminal plasma are useful as markers of ejaculate quality in donkey stallions.
\end{abstract}

Jack, ejaculate, biochemistry, enzyme, element

Seminal plasma is a complex combination of carbohydrates, proteins, minerals, vitamins and enzymes. It is a fluid that is mixed with the sperm during their transfer through the epididymis as part of the process of ejaculation and is produced by the epididymis and other associated sexual glands (Campanholi et al. 2017). This seminal plasma participates in the formation of the ejaculate, promotes the transport of sperm in the process of ejaculation and protects the sperm from the general effects occurring in the female genital tract. The physiological function of seminal plasma and its components has not yet been fully elucidated but it is known that it plays an important role in sperm maturation and metabolism, sperm activation and the pre-fertilization processes (Rodriguez-Martinez et al. 2011).

There are many studies that deal with the influence and function of seminal plasma across animal species which can be useful in understanding its presence in the ejaculate, fertility assessment and successful cooling or freezing of the semen, but with different results among species.

The aim of this study was to analyse the components of seminal plasma in domestic donkeys (Equus asinus) and to eventually find a link between its biochemical components

Address for correspondence: 
in relation to the volume, concentration and motility of sperm in the ejaculate. It can therefore be an important criterion for assessing the fertility and diagnosis of andrological disorders. To the authors' knowledge, such determination of parameters of seminal plasma in the domestic donkey has not been reported.

\section{Materials and Methods}

Animals and semen collection

Eleven ejaculates were collected from five domestic donkey stallions ranging in age from four to 16 years and weighing between 188 and $388 \mathrm{~kg}$. All stallions were clinically healthy before and during the study and were in the hands of private owners. All of them had unremarkable and different reproductive histories (two donkeys were housed together with jennies, two donkeys were used for breeding but were kept without jennies, one donkey was not used for breeding). During the study, they were individually housed in boxes under similar conditions. This study was approved by the Animal Protection and Welfare Committee of the University of Veterinary and Pharmaceutical Sciences Brno.

Semen from stallions was successfully collected after mounting a donkey female in oestrus using an artificial vagina (Missouri type, Insemination Technics and Supplies International Inc., Princeton, Ontario, Canada).

Ejaculate assessment

The ejaculate was assessed macroscopically after collection. To reduce the mucosal layer, the ejaculate was pre-filtered into a calibrated sterile glass beaker (Minitube, Tiefenbach, Germany) and the volume was measured. A drop of semen was deposited on a glass slide (Menzel-Glaser, Fisher Scientific, Thermo Fisher Scientific Inc., Waltham, Massachusetts, USA), coverslipped (Menzel-Glaser, cover CLIP, Fisher Scientific, Thermo Fisher Scientific Inc., Waltham, Massachusetts, USA) and then examined microscopically (Olympus CX 23, Olympus, Hamburg, Germany) for sperm motility. Then the sperm concentration in the ejaculate was measured using a photometer (Minitube photometer SDM 1 calibrated for equine, Minitube, Tiefenbach, Germany).

Seminal plasma

The ejaculate was placed into sterile plastic tubes in equal parts and then centrifuged (Hermle Z $206 \mathrm{~A}$, HERMLE Labortechnik GmbH, Wehingen, Germany) at $3074 \mathrm{~g}$ for $10 \mathrm{~min}$ to separate the seminal plasma from the sperm.

After centrifugation, the seminal plasma was aspirated using a long sterile needle attached to a sterile $20 \mathrm{ml}$ syringe (20 ml Luer PH Braun, B. Braun Melsungen AG, Hessen, Germany) and transferred to sterile Eppendorf tubes. The tubes were tagged, frozen to $-18{ }^{\circ} \mathrm{C}$ and stored until analysis.

Seminal plasma assessment

After all the samples had been collected, they were thawed and examined at the Large Animal Clinical Laboratory. The biochemical analysis was performed using a LIASYS spectrophotometric analyser (Analyzer Medical System, Guidonia, Italy). The following parameters were monitored: total protein, creatinine, urea, alkaline phosphatase (ALP), alanine-amino-transferase (ALT), aspartate-amino-transferase (AST), creatine kinase (CK), gamma-glutamyl-transferase (GGT), lactate-dehydrogenase (LDH). The concentration of the following microelements: sodium $(\mathrm{Na})$, potassium $(\mathrm{K})$, calcium $(\mathrm{Ca})$, phosphate $(\mathrm{P})$, chloride $(\mathrm{Cl})$, copper $(\mathrm{Cu})$, cholesterol (Chol), vitamin E (Vit E), magnesium (Mg), seminal plasma selenium (Se SP) and seminal plasma zinc ( $\mathrm{Zn} \mathrm{SP}$ ) was determined using flame atomic absorption spectrometry (Thermo Scientific ${ }^{\mathrm{TM}} \mathrm{iCE}^{\mathrm{TM}} 3500 \mathrm{AAS}$, Fisher Scientific, Thermo Fisher Scientific Inc., Waltham, Massachusetts, USA).

\section{Statistical analysis}

The statistical evaluation of the results was performed using a Spearman correlation test. The first evaluation between the analysed parameters of seminal plasma and sperm concentration, sperm motility and ejaculate volume was undertaken along with the second step correlation between the mean values of the seminal plasma parameters to the mean concentration values, sperm motility and ejaculate volume to eliminate the influence of an individual, because ejaculate parameters vary considerably also in different semen collections from one donkey. Significance was calculated by the correlation between selected ejaculate parameters (volume, concentration and sperm motility) and seminal plasma component values. These correlations were calculated in the above mentioned two steps because of the fact that a sample of five individuals is very small for a gross statistical analysis.

\section{Results}

The mean \pm SD and range of values of the basic parameters of ejaculate are shown in Table 1. The mean \pm SD and range of the measurement of selected parameters of seminal plasma is shown in Table 2. Both the significance of correlations between the mean seminal 
Table 1. Values of basic semen analysis.

\begin{tabular}{lccc}
\hline Semen parameter & $\mathrm{n}$ & Mean \pm SD & Range \\
\hline Volume $(\mathrm{ml})$ & 11 & $135.91 \pm 71.58$ & $20-300$ \\
Concentration $\left(\times 10^{6} / \mathrm{mm}^{3}\right)$ & 11 & $184.36 \pm 98.83$ & $62-439$ \\
Motility $(\%)$ & 11 & $80 \pm 10$ & $60-90$ \\
\hline
\end{tabular}

$\mathrm{n}$ - quantity; $\pm \mathrm{SD}-$ standard deviation

Table 2. Values of seminal plasma components.

\begin{tabular}{lccc}
\hline Seminal components & $\mathrm{n}$ & Mean $\pm \mathrm{SD}$ & Range \\
\hline Total protein $(\mathrm{g} / \mathrm{l})$ & 11 & $29.54 \pm 11.20$ & $13-49.5$ \\
Creatinin $(\mathrm{mmol} / \mathrm{l})$ & 11 & $231.23 \pm 115.11$ & $116.2-471.7$ \\
Urea $(\mathrm{mmol} / \mathrm{l})$ & 11 & $5.67 \pm 1.40$ & $3.04-7.26$ \\
Alkaline phosphatase $(\mu \mathrm{kat} / \mathrm{l})$ & 11 & $150,2 \pm 142.72$ & $23.4-542.4$ \\
Alanine-amino-transferase $(\mu \mathrm{kat} / \mathrm{l})$ & 11 & $0.13 \pm 0.10$ & $0-0.37$ \\
Aspartate-amino-transferase $(\mu \mathrm{kat} / \mathrm{l})$ & 11 & $2.32 \pm 1.78$ & $0.7-5.05$ \\
Creatine kinase $(\mu \mathrm{kat} / \mathrm{l})$ & 11 & $1.09 \pm 1.46$ & $0-4.98$ \\
Gamma-glutamyl-transferase $(\mu \mathrm{kat} / \mathrm{l})$ & 11 & $690.09 \pm 535.08$ & $72.7-1853$ \\
Lactate-dehydrogenase $(\mu \mathrm{kat} / \mathrm{l})$ & 11 & $7.69 \pm 6.75$ & $1.27-23.61$ \\
$\mathrm{Na}(\mathrm{mmol} / \mathrm{l})$ & 11 & $96.93 \pm 23.4$ & $46.3-118.1$ \\
$\mathrm{~K}(\mathrm{mmol} / \mathrm{l})$ & 11 & $23.23 \pm 14.12$ & $8.95-57.3$ \\
$\mathrm{Ca}(\mathrm{mmol} / \mathrm{l})$ & 11 & $4.29 \pm 5.22$ & $1.15-17.44$ \\
$\mathrm{P}(\mathrm{mmol} / \mathrm{l})$ & 11 & $2.28 \pm 0.31$ & $1.9-2.8$ \\
$\mathrm{Cl}(\mathrm{mmol} / \mathrm{l})$ & 11 & $110.77 \pm 8.35$ & $96.3-121.7$ \\
$\mathrm{Cu}(\mu \mathrm{g} / \mathrm{l})$ & 11 & $6.28 \pm 3.64$ & $1.44-11.98$ \\
$\mathrm{Mg}(\mu \mathrm{g} / \mathrm{l})$ & 11 & $5.22 \pm 6.77$ & $0.97-23.49$ \\
$\mathrm{Cholesterol}(\mathrm{mmol} / \mathrm{l})$ & 11 & $0.33 \pm 0.29$ & $0-0.69$ \\
$\mathrm{Vitamin} \mathrm{E}(\mathrm{mmol} / \mathrm{l})$ & 11 & $0.02 \pm 0.01$ & $0.01-0.05$ \\
$\mathrm{Se} \mathrm{SP}(\mu \mathrm{g} / \mathrm{l})$ & 11 & $12.77 \pm 7.19$ & $3.38-31.44$ \\
$\mathrm{Zn} \mathrm{SP}(\mu \mathrm{g} / \mathrm{l})$ & 11 & $11.43 \pm 6.92$ & $3.16-21.37$ \\
\hline & & & \\
\hline
\end{tabular}

$\mathrm{n}$ - quantity; $\pm \mathrm{SD}$ - standard deviation; $\mathrm{SP}$ - seminal plasma

plasma values and the mean ejaculate values and the significance of the correlations for all individual measurements were calculated and are presented in Table 3.

There was a significant positive correlation for both types (mean and individual) between ALP, AST, LDH, Cu, Se SP, Zn SP and the ejaculate concentration $(P<0.05)$. There was significant positive correlation between urea, $\mathrm{K}$ and $\mathrm{Mg}$ and the ejaculate volume in the evaluation of all individual measurements $(P<0.05)$. Significant positive correlation between Vit $\mathrm{E}$ and sperm motility was also found in the evaluation of the mean value $(P<0.05)$.

There was a borderline negative correlation between $\mathrm{Na}^{+}$and borderline positive correlation between ALT, Ca and $\mathrm{P}$ with the ejaculate volume of all individual measurements $(P<0.10$ and $P>0.05)$. Also there was a borderline positive correlation between $\mathrm{CK}$ and ejaculate concentration in the evaluation of all individual measurements $(P<0.10$ and $P>0.05)$. 
Table 3. Significance of correlations between mean seminal plasma values and mean ejaculate values, and between all seminal plasma values and all ejaculate values.

\begin{tabular}{|c|c|c|c|c|c|c|}
\hline \multirow[b]{2}{*}{ Parameter } & \multicolumn{3}{|c|}{ Mean } & \multicolumn{3}{|c|}{ All individual measurements } \\
\hline & Volume & Concentration & Motility & Volume & Concentration & Motility \\
\hline & $\mathrm{R}_{\mathrm{s}}$ & $\mathrm{R}_{\mathrm{s}}$ & $\mathrm{R}_{\mathrm{s}}$ & $\mathrm{R}_{\mathrm{s}}$ & $\mathrm{R}_{\mathrm{s}}$ & $\mathrm{R}_{\mathrm{s}}$ \\
\hline \multicolumn{7}{|l|}{ Total protein $(\mathrm{g} / \mathrm{l})$} \\
\hline \multicolumn{7}{|l|}{ Creatinin $(\mathrm{mmol} / \mathrm{l})$} \\
\hline Urea $(\mathrm{mmol} / \mathrm{l})$ & & & & $* *$ & & \\
\hline Alkaline phosphatase $(\mu \mathrm{kat} / \mathrm{l})$ & & ** & & & ** & \\
\hline Alanine-amino-transferase $(\mu \mathrm{kat} / \mathrm{l})$ & & & & $*$ & & \\
\hline Aspartate-amino-transferase $(\mu \mathrm{kat} / \mathrm{l})$ & & $* *$ & & & $* *$ & \\
\hline Creatine-kinase $(\mu \mathrm{kat} / \mathrm{l})$ & & & & & $*$ & \\
\hline \multicolumn{7}{|l|}{ Gamma-glutamyl-transferase ( $\mu$ kat/l) } \\
\hline Lactate-dehydrogenase $(\mu \mathrm{kat} / \mathrm{l})$ & & $* *$ & & & $* *$ & \\
\hline $\mathrm{Na}(\mathrm{mmol} / \mathrm{l})$ & & & & $*$ & & \\
\hline $\mathrm{K}(\mathrm{mmol} / \mathrm{l})$ & & & & $* *$ & & \\
\hline $\mathrm{Ca}(\mathrm{mmol} / \mathrm{l})$ & & & & $*$ & & \\
\hline $\mathrm{P}(\mathrm{mmol} / \mathrm{l})$ & & & & $*$ & & \\
\hline \multicolumn{7}{|l|}{$\mathrm{Cl}(\mathrm{mmol} / \mathrm{l})$} \\
\hline $\mathrm{Cu}(\mu \mathrm{g} / \mathrm{l})$ & & $* *$ & & & $* *$ & \\
\hline $\operatorname{Mg}(\mu \mathrm{g} / \mathrm{l})$ & & & & $* *$ & & \\
\hline \multicolumn{7}{|l|}{ Cholesterol (mmol/l) } \\
\hline Vitamin E (mmol/l) & & & $* *$ & & & \\
\hline $\operatorname{Se~SP}(\mu \mathrm{g} / 1)$ & & $* *$ & & & $* *$ & \\
\hline $\mathrm{Zn} \mathrm{SP}(\mu \mathrm{g} / 1)$ & & $* *$ & & & $* *$ & \\
\hline
\end{tabular}

\section{Discussion}

The constituents of seminal plasma and its composition seem to have different functions and characteristics for different animal species and breeds. It is uncertain if the influence of the breeding strategy (Gombar et al. 2017), the season of sexual activity (Koziorow skaGilun et al. 2011) or nutrition (Contri et al. 2011) play a role in the composition of the seminal plasma and if this composition influences the quality of the ejaculate. The basic point for a better understanding of how the seminal plasma influences the ejaculate and how important the role of the seminal plasma composition is in this process, is to know the seminal plasma component levels. Studies have been made in other domestic animal species but, as far as the authors are aware, this type of study in donkeys is one of the first.

It is known that, in equine stallions, the total protein concentration is lower in the pre-sperm ejaculate, whereas the first stage of the sperm fraction has the highest protein concentration (Koskinen et al. 2002). In our study, the total protein was not significantly correlated to any of the ejaculate parameters; however, a recent study in proteins of horse stallions does provide us with valuable information (Kareskoski and Katila 2008). On the other hand, it has been reported in rams that sperm viability disturbances may be associated with decreased protein levels in seminal plasma during spring or summer (Cardozo et al. 2006), which can reinforce that some proteins of seminal plasma play an important role in maintaining membrane stability of sperm cells (Strzezek et al. 2002) and are confirmed as very important components of seminal plasma. 
Creatinine and urea are well-known markers for the detection of urine in the ejaculate. Our results showed a significant positive correlation between urea and the ejaculate volume. Since the value of urospermia in donkey stallions is not available in the literature and a significant positive correlation is only available for the group of all measurements and there is no correlation in the mean values, we can only speculate on the significance of this positive correlation. But the values measured by us can be used in evaluating the contamination of the ejaculate with urine, when urospermia in macroscopic samples of the ejaculate is not detected. Furthermore, it is unknown if urea values can have a negative effect on sperm motility and fertility in domestic donkeys as reported in horses (Turner 2007). The creatinine concentration was not significant in any of the two assessment methods.

The concentration of the selected enzymes observed in this study showed different significance. Seminal plasma enzymes are very important to provide substrate energy, creating basic energy-generating bonds for sperm metabolism cycles, fertilization processes and preserving constant osmotic pressure during conservation (Dhami and Kodagali 1987). This study revealed a significant positive correlation in the activity of ALP, AST and LDH with sperm concentrations in both evaluated methods. Alkaline phosphatase is considered as an indicator of ejaculation in horses (Turner and McDonnell 2003). Increased activity of AST together with ALT in the ejaculate is attributed to the increasing secretory activity of male accessory sexual glands (Dhami and Kodagali 1987). Contrary to this assertion, we observed boundary significant positive correlation between the ejaculate volume and ALT in the evaluation group of all individual measurements. Regardless of origin, AST plays an important role in sperm metabolism through its incorporation into the cellular process (Dhami and Kodagali 1987). Dhami and Kodagali (1989) found that immobile sperm samples had significantly lower AST than samples of the ejaculate with motile sperm from Surti buffalo bulls. We did not confirm this finding in our study, but we did not have samples with low sperm motility. In the literature, data on LDH enzyme activity are very scarce and the higher values found here are unprecedented. It is uncertain whether the level of influence between higher LDH activity in seminal plasma on the ejaculate quality or if higher or lower LDH activity can be used as indicators of increased ejaculate quality (Diaconescu et al. 2014). Nevertheless, in another study in horse stallions, a high positive correlation was found between LDH and sperm motility (Pesch et al. 2006). In our study the CK enzyme showed borderline significance to sperm concentration during evaluation of all individual measurements, but no significance during the mean evaluation. A human CK enzyme study was performed to evaluate its use as an indicator of mature ejaculate sperm in men with oligospermia and reported elevated CK levels regardless of clinical diagnosis. The authors claimed that $\mathrm{CK}$ can be a sensitive indicator of the quality and maturity of the ejaculate in human male patients treated for male infertility (Hallak et al. 2001). It is reported that CK activity, along with other enzymes, is associated with semen quality, membrane function of the sperm and is incorporated into various processes during maturation (Bucci et al. 2014). The GMT enzyme is attributed to have an important function in the protection of sperm from oxidative stress and was found to be a good marker for semen freezing (Hinton et al. 1997). There are other studies that indicate a link between sperm motility and GMT in seminal plasma (Pesch et al. 2006; Kareskoski and Katila 2008), but in our study, no correlation with any of the evaluated parameters of the ejaculate (volume, concentration, and motility) was found. So based on the results of our study, we could not use the GMT activity as a useful marker in assessing the quality of the semen in the donkey stallions.

Ions $(\mathrm{Na}, \mathrm{K}, \mathrm{Cl}, \mathrm{Ca}, \mathrm{P}$ and $\mathrm{Mg}$ ) were also studied in this work. There was borderline significant negative correlation with $\mathrm{Na}^{+}$and a borderline positive correlation with $\mathrm{Ca}^{2+}$ and $\mathrm{P}$ in relation to ejaculate volume in the evaluation of all individual measurements. In general, $\mathrm{Na}^{+}$and $\mathrm{K}^{+}$are responsible for maintaining the osmotic equilibrium and 
osmolality of seminal plasma, which is essentially responsible for sperm activation (Zamiri et al. 2010). A study carried out in rams indicated an association of low levels of $\mathrm{Na}^{+}$and $\mathrm{K}^{+}$ ions in relation to low sperm motility (Zamiri et al. 2010). According to our results, this statement could not be confirmed in donkey stallions. There was only a highly significant positive correlation between $\mathrm{K}^{+}$and ejaculate volume in the evaluation of all individual measurements. Potassium ions are also intracellular cations and their concentrations could be an indicator of the integrity of the plasma membrane of the sperm (Zamiri and Khodaei 2005), but no significant relationship of $\mathrm{K}^{+}$in relation to motility was found in the correlation in both assessment methods (mean and individual). The $\mathrm{Cl}$ concentration was not significant in any of the two assessment methods, but there is a possibility that this anion may behave similar to other ions in maintaining the osmotic equilibrium of seminal plasma. There is a study describing the modulation of a number of ion channels (including chloride) in sperm, which is a characteristic phenomenon associated with the capability and acrosome response of mammalian sperm (Purohit et al. 1999). In our study, calcium had a borderline significant positive correlation with the ejaculate volume in the evaluation of all individual measurements. The function of calcium in seminal plasma is not clearly understood, but authors dealing with boar seminal plasma are recommending further research to determine the physiological extent of calcium concentration and to use it in combination with other biochemical variables as an indicator of semen quality (Zaja et al. 2016). Another crucial cation of seminal plasma is $\mathrm{Mg}^{2+}$ which has been found in the seminal plasma of boars, dependent on the ejaculate quality, with a higher quality having a higher concentration of $\mathrm{Mg}^{2+}$ (Lopez Rodriguez et al. 2013). From our research we can see a highly significant positive correlation between $\mathrm{Mg}^{2+}$ and the ejaculate volume in the evaluation of all individual measurements. Copper is needed for cytochrome oxidase, which is responsible for sperm energy supply and for cellular and humoral immunity (Leonhard-Marek 2001). The concentration of copper in seminal plasma in our results showed a highly significant positive correlation with the ejaculate concentration in both evaluation methods (mean and individual). A paper concentrating on stallions reported that increased copper concentrations reduced oxidative processes and glycolysis, which can lead to immobility and decreased viability of sperm (Pesch et al. 2006), but we did not find any correlation between copper levels and sperm motility. Our study did not show a correlation between cholesterol and volume, concentration or motility of the ejaculate in either assessment methods. However, a study of bulls with normozoosperma showed significantly higher levels of cholesterol and triacylglyceride in comparison with bulls with oligoasthenozoospermia (Cevik et al. 2008).

Vitamin $\mathrm{E}$ and its antioxidant function are relatively closely related to the trace element selenium. In our work we found a significant positive correlation between the concentration of Vit E in seminal plasma and ejaculate motility in the method of evaluating the mean measurements and significant positive correlation of Se SP to ejaculate concentration in both assessment methods. This finding can be confirmed by a study in stallions and rams demonstrating that parenteral supplementation of Vit $\mathrm{E}$ and selenium has a positive effect on the quality (Mahmoud et al. 2013) and quantity of the ejaculate (Contri et al. 2011; Mahmoud et al. 2013). As seen with selenium, a significant positive correlation was found with zinc. It is reported that in males, zinc and selenium are known trace elements important for normal reproductive functions (Villaverde et al. 2014). Both elements are involved in testicular development and spermatogenesis (Yamaguchi et al. 2009) and in addition, zinc is associated with maturation of epididymal sperm (Henkel et al. 2003), membrane stabilization, antioxidant and antibacterial function (Edstrom et al. 2008) and sperm motility modulation (Henkel et al. 2003).

The evaluation of the observed seminal plasma components and their relationship with the ejaculate parameters, along with the search for eventual markers of ejaculate quality, 
is rather complicated. To date, no biochemical assessment of seminal plasma in domestic donkey stallions has been performed to establish which parameters have a relationship with the ejaculate evaluation and quality. Clearly, in order to understand the effect of individual components on the quality of the ejaculate and to find potential markers, further studies with a much larger number of samples will be needed. This pilot study has shown that there is promising information for further research on this issue.

In conclusion, many significant correlations between enzymes, microelements and conventional semen parameters were observed in donkey seminal plasma. But only the enzymatic activities of ALP, AST, LDH and concentrations of $\mathrm{Cu}$, Se SP and Zn SP correlate significantly with semen concentration in both evaluated methods. For this reason, we consider these results to be the most compelling.

We also found significant correlations between the concentrations of urea, $\mathrm{K}^{+}, \mathrm{Mg}^{2+}$ and the ejaculate volume in the evaluation of all individual measurements and a correlation between Vit E concentration and sperm motility in the method of evaluating the mean measurements.

The evaluation of such a comprehensive biochemical profile of donkey seminal plasma is a pilot study dealing with this issue and may be the topic of further research.

\section{Acknowledgements}

This project was supported by grants no. IGA 105/216/FVL, IGA 114/2017/FVL, IGA 109/2018/FVL.

\section{References}

Bucci D, Isani G, Giaretta E, Spinaci M, Tamanini C, Ferlizza E, Galeati G 2014: Alkaline phosphatase in boar sperm function. Andrology 2: 100-106

Campanholi SP, Monteiro FM, Dias EAR, Mercadante MEZ, de Paz CCP, DellAqua JA Jr, Papa FO, DellAqua CPF, Vantini R, Garcia JM 2017: Effect of seminal plasma removal before cryopreservation of bovine semen obtained by electroejaculation on semen quality and in vitro fertility. Theriogenology 89: 114-121

Cardozo JA, Fernández-Juan M, Forcada F, Abecia A, Muiño-Blanco T, Cebrián-Pérez JA 2006: Monthly variations in ovine seminal plasma proteins analyzed by two-dimensional polyacrylamide gel electrophoresis. Theriogenology 66: 841-850

Cevik M, Tuncer PB, TaŞdemir U, Özgürtaş T 2008: Comparison of spermatological characteristics and biochemical seminal plasma parameters of normozoospermic and oligoasthenozoospermic bulls of two breeds. Turkish J Vet Anim Sci 31: 381-387

Contri A, De Amicis I, Molinari A, Faustini M, Gramenzi A, Robbe D, Carluccio A 2011: Effect of dietary antioxidant supplementation on fresh semen quality in stallion. Theriogenology 75: 1319-1326

Dhami AJ, Kodagali SB 1987: Correlation between biochemical and enzymatic constituents of semen of Surti buffalo bulls. Indian J Anim Sci 57: 1283-1286

Dhami AJ, Kodagali SB 1989: Comparative analysis of physio-biochemical attributes in static and motile semen ejaculates from Surti buffalo bulls. Indian J Anim Sci 59: 344-347

Diaconescu C, Matei M, Talpu G, Tapaloaga P 2014: Comparative physicochemical and biochemical characterization of bull and boar semen. Scientific Papers. Series D. Anim Sci J 57: 141-145

Edstrom AM, Malm J, Frohm B, Martellini JA, Giwercman A, Morgelin M, Cole AM, Sorensen OE 2008: The major bactericidal activity of human seminal plasma is zinc-dependent and derived from fragmentation of the semenogelins. J Immun 181: 3413-3421

Gombar R, Pitcher TE, Lewis JA, Auld J, Vacratsis PO 2017: Proteomic characterization of seminal plasma from alternative reproductive tactics of Chinook salmon (Oncorhynchus tswatchysha). J Proteom 157: 1-9

Hallak J, Sharma RK, Pasqualotto FF, Ranganathan P, Thomas AJ, Agarwal A 2001: Creatine kinase as an indicator of sperm quality and maturity in men with oligospermia. Urology 58: 446-451

Henkel R, Baldauf C, Schill WB 2003: Resorption of the element zinc from spermatozoa by the epididymal epithelium. Reprod Dom Anim 38: 97-101

Hinton BT, Lan ZJ, Rudolph DB, Labus JC, Lye RJ 1997: Testicular regulation of epididymal gene expression. Supplement. J Reprod Fert 53: 47-57

Kareskoski M, Katila T 2008: Components of stallion seminal plasma and the effects of seminal plasma on sperm longevity. Anim Reprod Sci 107: 249-256

Koskinen E, Karlsson M, Reilas T, Sankari S, Esala AL, Katila T 2002: Catalase activity and total protein in fractionated stallion seminal plasma. Theriogenology 58: 337-340

Koziorowska-Gilun M, Koziorowski M, Fraser L, Strzezek J 2011: Antioxidant defence system of boar cauda epididymial spermatozoa and reproductive tract fluids. Reprod Dom Anim 46: 527-533 
Leonhard-Marek S 2001: Influence of drugs, pollution and trace elements on male fertility. In: Busch W, Holzmann A (Eds): Andrology in veterinary medicine. Schattauer, Stuttgart, pp. 474-481

Lopez Rodriguez A, Rijsselaere T, Beek J, Vyt P, Van Soom A, Maes D 2013: Boar seminal plasma components and their relation with semen quality. Syst Biol Reprod Med 59: 5-12

Mahmoud GB, Abdel-Raheem SM, Hussein HA 2013: Effect of combination of vitamin E and selenium injections on reproductive performance and blood parameters of Ossimi rams. S Rumin Res 113: 103-108

Pesch S, Bergmann M, Bostedt H 2006: Determination of some enzymes and macro-and microelements in stallion seminal plasma and their correlations to semen quality. Theriogenology 66: 307-313

Purohit SB, Laloraya M, Kumar GP 1999: Role of ions and ion channels in capacitation and acrosome reaction of spermatozoa. Asian J Androl 1: 107

Rodriguez-Martinez H, Kvist U, Ernerudh J, Sanz L, Calvete JJ 2011: Seminal plasma proteins: what role do they play? Am J Reprod Immunol 66: 11-22

Strzezek J, Saiz-Cidoncha F, Wysocki P 2002: Seminal plasma proteins as markers of biological value of boar semen. Anim Sci Pap Rep 20: 255-266

Turner RMO 2007: Urospermia and hemospermia. In: Samper JC, Pycock JF, McKinnon AO (Eds): Current therapy in equine reproduction. St. Louis, Saunders, pp. 258-265

Turner RMO, McDonnell SM 2003: Alkaline phosphatase in stallion semen: characterization and clinical applications. Theriogenology 60: 1-10

Villaverde AIS, Fioratti EG, Ramos RS, Neves RC, Ferreira JCP, Cardoso GS, Padilha PM, Lopes MD 2014: Blood and seminal plasma concentrations of selenium, zinc and testosterone and their relationship to sperm quality and testicular biometry in domestic cats. Anim Reprod Sci 150: 50-55

Yamaguchi S, Miura C, Kikuchi K, Celino FT, Agusa T, Tanabe S, Miura T 2009: Zinc is an essential trace element for spermatogenesis. Proc Nat Acad Sci 106: 10859-10864

Zaja IZ, Samardzija M, Vince S, Majic-Balic I, Vilic M, Duricic D, Milinkovic-Tur S 2016: Influence of boar breeds or hybrid genetic composition on semen quality and seminal plasma biochemical variables. Anim Reprod Sci 164: 169-176

Zamiri MJ, Khalili B, Jafaroghli M, Farshad A 2010: Seasonal variation in seminal parameters, testicular size, and plasma testosterone concentration in Iranian Moghani rams. S Rumin Res 94: 132-136

Zamiri MJ, Khodaei HR 2005: Seasonal thyroidal activity and reproductive characteristics of Iranian fat-tailed rams. Anim Reprod Sci 88: 245-255 